\title{
A Review of Complementary Assets
}

\author{
Xiaolin Zhou \\ School of Management, Jinan University, Guangzhou, China \\ Email: zx1434gg@gmail.com
}

How to cite this paper: Zhou, X.L. (2019) A Review of Complementary Assets. American Journal of Industrial and Business Management, 9, 1772-1780.

https://doi.org/10.4236/ajibm.2019.99116

Received: August 9, 2019

Accepted: September 2, 2019

Published: September 5, 2019

Copyright $\odot 2019$ by author(s) and Scientific Research Publishing Inc. This work is licensed under the Creative Commons Attribution International License (CC BY 4.0).

http://creativecommons.org/licenses/by/4.0/

\begin{abstract}
What attracts the increasing number of scholars' attention was that the innovators were often not the biggest beneficiaries of technological innovation. Teece came up with the concept of complementary assets to solve this problem, after which complementary assets have gradually become the hot topic of scientific research. This essay summarized the definition, classification, measurement of complementary assets as well as the relationship between complementary assets and innovation and commercialization that was proposed by scholars at home and abroad. At the same time, a brief view of current research situation of complementary assets was made. In the end, some thoughts on the further development of complementary assets were presented.
\end{abstract}

\section{Keywords}

Complementary Assets, Technology Innovation, Technology

Commercialization

\section{Introduction}

With the proposal of building an innovative national strategy, enhancing the capacity for independent innovation has become the strategic focus for science and technology development. Continuous technological innovation is the core competitiveness of enterprise development, but more and more examples show that innovative companies often cannot benefit from innovation, while consumers, imitators and other industry members benefit from this phenomenon. To explain this, Teece first proposed the concept of complementary assets in the PFI theoretical model proposed in 1986. He believes that the commercialization of any technological achievements is inseparable from the support of assets including manufacturing, marketing and after-sales service [1]. The concept of complementary assets has attracted the attention of scholars at home and abroad. The research mainly focuses on the definition, classification, measurement, asset 
acquisition methods and complementary assets and commercialization, innovation and entrepreneurship relationship of complementary assets. This paper intends to review the research status of the concept of complementary assets and provide some insight for future research directions.

\section{Definition of Complementary Assets}

The definition of complementary assets by domestic and foreign scholars is mainly defined from the following perspectives. The first one is based on the value chain perspective. Teece (1986) believes that complementary assets are located downstream of technological innovation chain, which including assets for innovation, such as manufacturing, marketing, and after-sales services, assets [1]. Since then, Taylor and Helfat (2009) have extended the view of Teece (1986) that complementary assets include tangible assets, intangible assets and organizational capabilities [2]. The second definition is based on whether the interrelationship between assets is a synergistic or alternative perspective. Dyer and Singn (1998) define complementary assets as unique resources of alliance partners that collectively generate greater rents, exceeding the sum of individual partners' resource endowments [3]. The third definition is based on the role of asset growth. Xiong and Zhang (2011) divide enterprise assets into core assets and complementary assets. Core assets are assets that support the core products or core businesses of the enterprise; complementary assets are with core assets, which play a role in the production and management activities of enterprises [4].

In summary, the study of complementary assets reveals that scholars have a relatively simple definition of complementary assets, which basically follows Teece's (1986) definition, namely, factors such as manufacturing capabilities, distribution channels, service networks and complementary technologies that are closely related to breakthroughs in technological innovation and commercialization. As a result, further research on complementary assets is limited.

\section{Classification of Complementary Assets}

The classification of complementary assets determines different research directions. Therefore, Home and broad scholars have proposed many different classifications of complementary assets. The main methods are divided into three types. The first category is to classify the dependence of different product commercialization processes on different complementary assets. For example, Teece (1986) divides complementary assets into general, specialized, and co-professional complementary assets. The main difference lies in the availability and imitation of market transactions. This is the most initial classification of complementary assets and the most classic one. The second category is mainly based on the function of the asset/industry chain. For example, Fang (2011) divides complementary assets into complementary assets of marketing, manufacturing, suppliers, finance and social relations according to the functional classification of assets in the industrial chain, and enterprise information facilities are also considered [5]. Taking into account the development of the times, He et al. (2016) di- 
vided the complementary assets of the Internet era into production (competitive production capacity, supplier relationship), sales (sales channels, customer relationships, user scale, brand influence) and service classes (service capabilities, complementary products/technologies, service resource integration capabilities), and complementary assets show pertinence and timeliness [6]. The third category is based on the source of complementary assets. For example, Soh and Yu (2010) divide the complementary assets of telecommunications industry into market-based assets and non-market-based assets. Non-market-based assets include: $\mathrm{R} \& \mathrm{D}$ subsidies and tax incentives, the establishment of licenses, management and operation, and political relations. Market-based assets include: localized expertise, customer experience, brand name and channel management experience [7]. Fang (2012) divides the complementary assets into internal and external complementary assets according to their degree of ownership and control, and proposes that the internal complementary assets are assets fully owned by the enterprise, and the rest belong to external complementary assets [8].

According to extant literature, researchers of different academic backgrounds have different ways of classification, and there is no census, but in general they have not left the scope of the concept of complementary assets proposed by Teece (1986), which is manufacturing, marketing, after-sales service and other supporting assets. At present, the most popular classification method is divided into complementary assets such as marketing, production and human resources according to different functions, and analyzes the impact of different types of complementary assets on the relationship between technical diversity and performance.

\section{Measurement of Complementary Assets}

In relevant empirical research on complementary assets, many scholars have given indicators for the measurement of complementary assets in different industries. There are two main methods for measuring indicators: questionnaires and objective data on business operations. The most common measure is Christmann (2000) and Song (2005). They used questionnaires to interview business operators to obtain complementary assets of the company, such as asking whether the company has advanced manufacturing equipment related to technological innovation or manufacturing operations technology to measure the manufacturing complementary assets of the enterprise [9] [10]. In addition to questionnaires, scholars also attempt to measure complementary assets using objective data from business operations. Considering the impact of technological diversity on performance and the interaction effect of professional complementary assets, Chiu (2008) divided complementary assets into marketing resources, production resources and human capital, and used sales expenses, indirect manufacturing costs and labor costs for measurements respectively [11]. On the basis of Chiu (2008), Chen et al. (2015) divide the sales expenses and salary expenses by the annual operating income of the enterprise in order to eliminate the scale effect of the enterprise, and obtain sales expense rate and salary expense rate to measure 
marketing complementary assets and human complementary assets. Manufacturing complementary assets use the net value rate, that is, the net value of machinery and equipment at the end of the year divided by the original value of machinery and equipment at the end of the year [12].

The comprehensive literature shows that there are not many methods for measuring complementary assets, and the measurement of complementary assets often uses the data of the questionnaire for a company or an industry. Consequently, conclusions from these questionnaire data are often not very representative and there may be more errors caused by human factors. At the same time, many scholars choose to use objective data to measure complementary assets, but most of the objective data take the operating expenses of the enterprise, and cannot fully cover the meaning of complementary assets. Furthermore, the operating expenses are a static indicator, which does not reflect the dynamic change of complementary assets over time. In other word, the indicators are not targeted and time-sensitive. In addition, very few indicators have been measured according to the classification based on the degree of dependence of complementary assets proposed by Teece's (1986).

\section{Relationship between Complementary Assets and Innovation}

\subsection{Technological Innovation}

In the relationship between complementary assets and innovation, research in the past decade has focused on industries and enterprises from technology-intensive manufacturing, bio-pharmaceutical, and telecommunications industries. It is mainly divided into three aspects. First, the impact of complementary assets is owned by incumbent companies on the choice of enterprise innovation strategy. For example, Rothaermel's (2001) found that incumbent companies have achieved strategic growth by leveraging the advantages of their complementary assets to form strategic alliances with newcomers, with network strategies focused on mining complementary assets. The performance of enterprises is better than those that focus on exploring new technologies, but as the strength of the alliance increases, it will show a diminishing marginal return [13]. Since then, scholars have studied the strategic alliance between incumbents and newcomers. Recently, Asebro and Serrano (2015) surveyed independent inventors in Canada found that independent inventors established business teams with others primarily to commercialize innovation with other complementary assets such as funds in the team. It shows that complementary assets also affect the individual's choice of patents. In addition, complementary assets can also influence the strategic choice between the incumbent and its core employees. Colombo and Dawid (2016) believe that the search friction of incumbent companies in the complementary asset market has a positive effect on the innovator's investment in innovation, which means that the existence of complementary assets reduces the possibility of forming new businesses due to the departure of key R\&D employees [14]. The second type of research is about the impact of 
complementary assets on the type of innovation. Almost all studies draw consistent conclusions. Complementary assets can make enterprises dependent, which is not conducive to the development of breakthrough innovation. For example, Thomke and Kuemmerle (2002) found that companies with more complementary assets tend to increase innovation and neglect radical innovation, because the complementary technologies and R\&D complementary assets formed in the past R\&D activities will provide themselves with many new technological opportunities within the original technology system [15]. Lai and Chiu et al. (2010) also hold the opinion that complementary assets will enable companies to develop along the original technology trajectory, and new technologies are dependent on the company's original internal technology [16]. The third category is the impact of complementary assets on the formation of innovation, and most of the researches treat complementary assets as a regulatory variable. Li and Fang (2010) proposed to enhance the breakthrough innovation capability through different complementary assets based on the resource-capability-performance theoretical framework of enterprise resource strategy, that is, to actively increase radical innovation capability. In turn, it affects enterprises' radical innovation performance [17]. This theory opens the black box of complementary asset operating mechanisms. The fourth category is the role of complementary assets in technological innovation. Xiong and Fang (2010) found that the impact of different types of complementary assets on radical innovation is different through the survey of listed companies. Complementary manufacturing and human assets are not conducive to radical technological innovation, and the accumulation of complementary marketing assets is conducive to radical technological innovation [18]. In the latest research, Alvarez-Garrido and Dushnitsky (2016) found that the innovation performance is influenced by the type of investors, that is, the innovation output rate of investment by corporate investors is higher than that of independent investors because they have more complementary assets needed for innovative companies [19].

Based on literature above, it can be found that the research on complementary assets mainly focuses on the relationship between complementary assets and technological innovation, and the research topics are colorful, but the extant research lack more in-depth and specific research. For example, almost all research holds a positive view of complementary assets, and few scholars explore which complementary assets are not applicable to a particular stage of a particular type of business. Such as a high-tech enterprise in the startup phase, human complementarity assets are obviously more important than marketing complementary assets. Only firms with products developed independently can have the opportunity to use marketing to promote considering that $\mathrm{R} \& \mathrm{D}$ capabilities are most needed in initial stage.

\subsection{Innovative Commercialization}

In early days, many scholars felt that something was helping big companies to monopolize the benefits of innovation, but the explanation was limited to the 
issue of monopoly rights at the market level. After Teece (1986) proposed the concept of complementary assets, scholars generally realized that complementary assets provided the necessary conditions for innovation commercialization. The research on the relationship between complementary assets and innovative commercialization at home and abroad is mainly divided into two aspects. The first is the impact of different types of complementary assets on the commercialization of innovation. For example, Rothaermel and Hill (2005) empirically analyze panel data in the four years of computer, steel, pharmaceutical, and communications industries, suggesting that proprietary complementary assets that cannot be obtained from the market are complementary assets necessary for innovative commercialization [13]. López and Roberts (2002) argue that when companies lack the innovation-related manufacturing complementary assets, it is difficult to achieve rapid innovation and rapid production, and may lose innovation market initiative and innovation profits. And companies with fully manufacturing proprietary complementary assets can not only quickly introduce innovative products into the market, but also occupy high market share [20]. The second is the study of the impact of complementary assets on the commercialization of technology in different environments, that is, the study of the interaction of the relationship between complementary assets and innovative commercialization. For example, through data research on 404 Chinese companies, Cai and Gao (2012) found that the dynamics of technology and market will weaken the relationship between technological capabilities and technology commercialization; when technological dynamics improve, the promotion of proprietary complementary assets to technology commercialization will also be weakened [21]. Lin and Wang (2015) found that market perception can positively adjust the relationship between complementary assets and patent commercialization performance through a survey of Taiwanese biotech companies, but this regulation is not significant [22]. At the same time, Fuentelsaz et al. (2015) also empirically found through the telecommunication industry data that after radical technological changes, complementary assets enable the incumbents to maintain their relationship in the business network, so the performance of the incumbent is higher than the new one [23]. The third is the use of complementary assets to explain the phenomenon of technological catch-up. For example, Luo and Ma (2013) believe that complementary assets are the key elements that constitute the catch-up of the late-stage enterprises. The entry of enterprises into a certain market does not depend mainly on technological innovation, but through the re-integration of complementary assets. Innovative forms of combined industrial organization, or relying on relevant support policies such as government market access protection for specific periods (such as enterprises in developing countries) to gain competitive advantage. In addition to theoretical analysis, Gao et al. (2014) divided the four quadrants according to the level of technical barriers and the level of complementary assets, and conducted a game analysis between the enterprises in the incumbent countries and in the subsequent countries in each quadrant. For example, when the technical barriers are low and the com- 
plementary assets are difficult, the initiative to obtain the technology upgrade of the industry is not in the hands of the technology-based enterprises, but is in the market complementary to the commercialization of new products and complementary product resources, whose choice of new products determines the direction of technological development of the industry.

Based on the above-mentioned literature, the early research on the complementary commercialization of complementary assets and technological innovation mainly focused on theoretical research, that is, the impact of different types of complementary assets on the commercialization performance of enterprises. The recent exploration of this issue mainly focuses on the use of objective data to explore the role of complementary assets as a dependent variable in considering the external environment to regulate commercial performance, but the complementary assets have not opened the black box of technology commercialization which means no scholars have in-depth exploration of the mechanism by which complementary assets affect commercial performance.

\section{Conclusions}

For the study of complementary assets, home and abroad scholars focus on the definition, classification, measurement methods of complementary assets and use theoretical analysis or objective data to explore the relationship between complementary assets and entrepreneurship and commercialization and the importance of complementary assets for successful technological innovation is realized. However, the following shortcomings still exist. First, the current exploration of complementary assets is mainly theoretical, and theoretically, there is no other framework for the concept of complementary assets proposed by Teece. Second, due to data source limitations and collection difficulties, extant research on the relationship between complementary assets and technological innovation is still limited to the corporate or industry level. Third, most studies only show the importance of complementary assets, but there is not much empirical research on how the increase and accumulation of complementary assets have an impact on the technological innovation performance.

We believe that the direction of complementary assets in the future can be considered. First, using more objective and dynamic data to explore complementary assets, the dynamic evolution analysis of complementary assets of enterprises or industries can be based on data from different periods, but the selection and credibility still require further exploration. Second, complementary assets are one of the premises for enterprise innovation's commercialization. At the same time, there are certain risks in technology commercialization. Research on exploring the adjustment effect of different types of complementary assets on commercialization risk based on resource-based view is needed. Third, science and technology intermediary is a way to acquire complementary assets. In future, we could consider the method of social network analysis to explore the impact of technology intermediaries on corporate technology business performance. 


\section{Conflicts of Interest}

The author declares no conflicts of interest regarding the publication of this paper.

\section{References}

[1] Teece, D.J. (1986) Profiting from Technological Innovation: Implications for Integration, Collaboration, Licensing and Public Policy. Research Policy, 15, 285-305. https://doi.org/10.1016/0048-7333(86)90027-2

[2] Taylor, A. and Helfat, C.E. (2009) Organizational Linkages for Surviving Technological Change: Complementary Assets, Middle Management, and Ambidexterity. Organization Science, 20, 718-739. https://doi.org/10.1287/orsc.1090.0429

[3] Dyer, J.H. and Singh, H. (1988) The Relational View: Cooperative Strategy and Sources of Interorganizational Competitive Advantage. Academy of Management Review, 23, 660-679. https://doi.org/10.5465/amr.1998.1255632

[4] Wang, Y. and Rajagopalan, N. (2015) Alliance Capabilities: Review and Research Agenda. Journal of Management, 41, 236-260. https://doi.org/10.1177/0149206314557157

[5] Åstebro, T. and Serrano, C.J. (2015) Business Partners: Complementary Assets, Financing, and Invention Commercialization. Journal of Economics \& Management Strategy, 24, 228-252. https://doi.org/10.1111/jems.12095

[6] Zahra, S.A. and George, G. (2002) Absorptive Capacity: A Review, Reconceptualization, and Extension. Academy of Management Review, 27, 185-203.

https://doi.org/10.5465/amr.2002.6587995

[7] Pek-Hooi, S. and Jiang, Y. (2010) Institutional Environment and Complementary Assets: Business Strategy in China's 3G Development. Asia Pacific Journal of Management, 27, 647-675. https://doi.org/10.1007/s10490-008-9121-4

[8] Fang, X.B. (2012) Research on the Resistance of Organizational Inertia to the Utilization of External Complementary Assets and Its Elimination Mechanism. Science and Technology Management Research, 12, 224-226.

[9] Song, M., Droge, C., Hanvanich, S., et al. (2005) Marketing and Technology Resource Complementarity: An Analysis of Their Interaction Effect in Two Environmental Contexts. Strategic Management Journal, 26, 259-276. https://doi.org/10.1002/smj.450

[10] Christmann, P. (2000) Effects of "Best Practices" of Environmental Management on Cost Advantage: The Role of Complementary Assets. Academy of Management Journal, 43, 663-680. https://doi.org/10.5465/1556360

[11] Chiu, Y., Lai, H., Lee, T., et al. (2008) Technological Diversification, Complementary Assets, and Performance. Technological Forecasting and Social Change, 75, 875-892. https://doi.org/10.1016/j.techfore.2007.07.003

[12] Frank, T.R. and Charles, W.L. (2005) Technological Discontinuities and Complementary Assets: A Longitudinal Study of Industry and Firm Performance. Organization Science, 16, 52-70. https://doi.org/10.1287/orsc.1040.0100

[13] Rothaermel, F.T. (2001) Incumbent's Advantage through Exploiting Complementary Assets Viainter firm Cooperation. Strategic Management Journal, 22, 687. https://doi.org/10.1002/smj.180

[14] Colombo, L. and Dawid, H. (2016) Complementary Assets, Start-Ups and Incentives to Innovate. International Journal of Industrial Organization, 44, 177-190. 
https://doi.org/10.1016/j.ijindorg.2015.11.003

[15] Thomke, S. and Kuemmerle, W. (2002) Asset Accumulation, Interdependence and Technological Change: Evidence from Pharmaceutical Drug Discovery. Strategic Management Journal, 23, 619. https://doi.org/10.1002/smj.242

[16] Lai, H., Chiu, Y., Liaw, Y., et al. (2010) Technological Diversification and Organizational Divisionalization: The Moderating Role of Complementary Assets. British Journal of Management, 21, 983-995. https://doi.org/10.1111/j.1467-8551.2009.00630.x

[17] Chungwon, W., et al. (2014) Exploring the Impact of Complementary Assets on the Environmental Performance in Manufacturing SMEs. Sustainability, 6, 7412-7432. https://doi.org/10.3390/su6107412

[18] Hess, A.M. and Rothaermel, F.T. (2011) When Are Assets Complementary? Star Scientists, Strategic Alliances, and Innovation in the Pharmaceutical Industry. Strategic Management Journal, 32, 895-909. https://doi.org/10.1002/smj.916

[19] Alvarez-Garrido, E. and Dushnitsky, G. (2016) Are Entrepreneurial Venture's Innovation Rates Sensitive to Investor Complementary Assets? Comparing Biotech Ventures Backed by Corporate and Independent VCs. Strategic Management Journal, 37, 819-834. https://doi.org/10.1002/smj.2359

[20] López, L.E. and Roberts, E.B. (2002) First-Mover Advantages in Regimes of Weak Appropriability: The Case of Financial Services Innovations. Journal of Business Research, 55, 997. https://doi.org/10.1016/S0148-2963(01)00200-4

[21] Teece, D.J. (2007) Explicating Dynamic Capabilities: The Nature and Microfoundations of (Sustainable) Enterprise Performance. Strategic Management Journal, 28, 1319-1350. https://doi.org/10.1002/smj.640

[22] Lin, J. and Wang, M. (2015) Complementary Assets, Appropriability, and Patent Commercialization: Market Sensing Capability as a Moderator. Asia Pacific Management Review, 20, 141-147. https://doi.org/10.1016/j.apmrv.2014.12.013

[23] Fuentelsaz, L., Garrido, E. and Maicas, J.P. (2015) Incumbents, Technological Change and Institutions: How the Value of Complementary Resources Varies across Markets. Strategic Management Journal, 36, 1778-1801.

https://doi.org/10.1002/smj.2319 